\title{
Empowering the crowd:
}

feasible strategies for epidemic management in high-density

\section{informal settlements. The case of COVID-19 in Northwest Syria}

\section{Journal Article}

Author(s):

Pascual-García, Alberto; Klein, Jordan D.; Villers, Jennifer; Campillo-Funollet, Eduard; Sarkis, Chamsy

Publication date:

2021-01

Permanent link:

https://doi.org/10.3929/ethz-b-000504178

\section{Rights / license:}

Creative Commons Attribution-NonCommercial 4.0 International

Originally published in:

BMJ Global Health 6(8), https://doi.org/10.1136/bmjgh-2020-004656 


\title{
BMJ Global Health Empowering the crowd: feasible strategies for epidemic management in high-density informal settlements. The case of COVID-19 in Northwest Syria
}

\author{
Alberto Pascual-García (D) , ${ }^{1}$ Jordan D Klein (D) , ${ }^{2}$ Jennifer Villers (D) , ${ }^{3}$ \\ Eduard Campillo-Funollet (D) , ${ }^{4}$ Chamsy Sarkis ${ }^{5}$
}

To cite: Pascual-García $A$ Klein JD, Villers J, et al. Empowering the crowd: feasible strategies for epidemic management in high-density informal settlements. The case of COVID-19 in Northwest Syria. BMJ Global Health 2021;6:e004656. doi:10.1136/ bmjgh-2020-004656

Handling editor Seye Abimbola

- Additional online supplemental material is published online only. To view, please visit the journal online (http://dx.doi.org/10.1136/ bmjgh-2020-004656).

JV and EC-F contributed equally.

Received 8 December 2020 Accepted 14 July 2021

Check for updates

(C) Author(s) (or their employer(s)) 2021. Re-use permitted under CC BY-NC. No commercial re-use. See rights and permissions. Published by BMJ.

For numbered affiliations see end of article.

Correspondence to Dr Alberto Pascual-García; alberto.pascual@env.ethz.ch

\section{ABSTRACT}

More than 1 billion people live in informal settlements worldwide, where precarious living conditions pose unique challenges to managing a COVID-19 outbreak. Taking Northwest Syria as a case study, we simulated an outbreak in high-density informal Internally Displaced Persons (IDP) camps using a stochastic Susceptible-ExposedInfectious-Recovered model. Expanding on previous studies, taking social conditions and population health/ structure into account, we modelled several interventions feasible in these settings: moderate self-distancing, selfisolation of symptomatic cases and protection of the most vulnerable in 'safety zones'. We considered complementary measures to these interventions that can be implemented autonomously by these communities, such as buffer zones, health checks and carers for isolated individuals, quantifying their impact on the micro-dynamics of disease transmission. All interventions significantly reduce outbreak probability and some of them reduce mortality when an outbreak does occur. Self-distancing reduces mortality by up to $35 \%$ if contacts are reduced by $50 \%$. A reduction in mortality by up to $18 \%$ can be achieved by providing one self-isolation tent per eight people. Protecting the most vulnerable in a safety zone reduces the outbreak probability in the vulnerable population and has synergistic effects with the other interventions. Our model predicts that a combination of all simulated interventions may reduce mortality by more than $90 \%$ and delay an outbreak's peak by almost 2 months. Our results highlight the potential for non-medical interventions to mitigate the effects of the pandemic. Similar measures may be applicable to controlling COVID-19 in other informal settlements, particularly IDP camps in conflict regions, around the world.

\section{INTRODUCTION}

The spread of airborne infectious diseases with pandemic potential in regions immersed in protracted armed conflicts, with large displaced populations, is an important challenge. ${ }^{1}$ When the displaced population exceeds official resettlement and refugee camp capacity, internally displaced persons

\section{Key questions}

What is already known?

- Since the onset of the COVID-19 pandemic, many studies have provided evidence for the effectiveness of strategies such as social distancing, testing, contact tracing, case isolation, use of personal protective equipment/face masks and improved hygiene to reduce the spread of the disease. These studies underlie the recommendations of WHO, but their implementation is contingent on local conditions and resources.

- Mathematical modelling is the basis of many epidemiological studies and has helped inform policymakers considering COVID-19 responses around the world. Nevertheless, only a limited number of studies have applied these models to informal settlements.

\section{What are the new findings?}

- We developed a mathematical model to study the dynamics of COVID-19 in Syrian internally displaced persons (IDP) camps, elaborating on previous efforts done in similar settings by explicitly parameterising the camps' demographics, living conditions and microdynamics of interpersonal contacts in our modelling.

- We designed interventions such as self-distancing self-isolation and the creation of safety zones to protect the most vulnerable members of the population, through conversations with camp managers. We ensured that our proposed interventions would be feasible and have community buy-in.

- Our results show how low-cost, feasible, communityled non-medical interventions can significantly mitigate the impact of COVID-19 in Northwest Syrian IDP camps.

(IDPs) must live in informal settlements (hereafter named 'camps'). These regions must contend with the public health challenges resulting from violence, ${ }^{2}$ the deterioration of health systems, ${ }^{3}$ especially of critical care, ${ }^{4}$ and the breakdown of essential public infrastructure such as water and sanitation 


\section{Key questions}

What do the new findings imply?

- Our model represents a step forward in the much-needed search for epidemiological models that are sufficiently flexible to consider specific social contexts. The model can also help inform similar interventions in refugee camps in conflict-torn regions, and potentially be adapted to other informal settlements and vulnerable communities around the world.

systems. ${ }^{5}$ Urgent action is needed to contain the spread of disease in these settings, a task which necessarily involves the engagement of the communities living in them. ${ }^{6}$

This study focuses on the spread of COVID-19 in the Northwest region of Syria (NWS): a relatively small geographical area with 4.2 million people, of which 1.15 million $(27.4 \%)$ are IDPs living in camps, ${ }^{7}$ and where the number of cases increased 20 -fold between 8 September and 20 October $2020 .{ }^{8}$ The health status of households in camps in NWS is poor; $24 \%$ have a member with a chronic disease, of whom $41 \%$ have no access to medicines. ${ }^{9}$ As in other conflict regions, the political instability in NWS hinders coordinated public health actions, and the ongoing movements of IDPs create ample opportunity for infectious disease transmission, while making contact tracing interventions infeasible.

To investigate feasible COVID-19 prevention interventions in the camps, we considered a Susceptible-ExposedInfectious-Recovered model similar to the one presented by Gatto et $a l^{10}$ in which the camps' populations are divided into classes reflecting their estimated age structures and comorbidity prevalence. We use this model to propose various interventions aimed at reducing the number of contacts within and between population classes in general, and with symptomatic individuals in particular. We paid special attention to how the living conditions in informal camps inform the assumptions underlying our proposed interventions, a question often neglected. ${ }^{11}$ We modelled interventions previously proposed for African cities, ${ }^{12}$ such as self-distancing, isolation of symptomatic individuals and the creation of a 'safety zone' in which more vulnerable members of the population are protected from exposure to the virus.

Building on the approach used to model the impact of these interventions in African cities, our model includes a parameterisation of the number of contacts each individual has per day. ${ }^{12}$ We further elaborate on this approach by making a more explicit representation of contacts and other parameters in the model. We consider the microdynamics of contacts, the effect of having carers to attend to isolated individuals, and the existence of a buffer zone in which exposed and protected population classes can interact under certain rules. We examine a potential worst-case scenario in which there is no access to any healthcare facility. Since empowering local communities in conflict regions to understand how to control diseases like COVID-19 is possibly the most (and perhaps

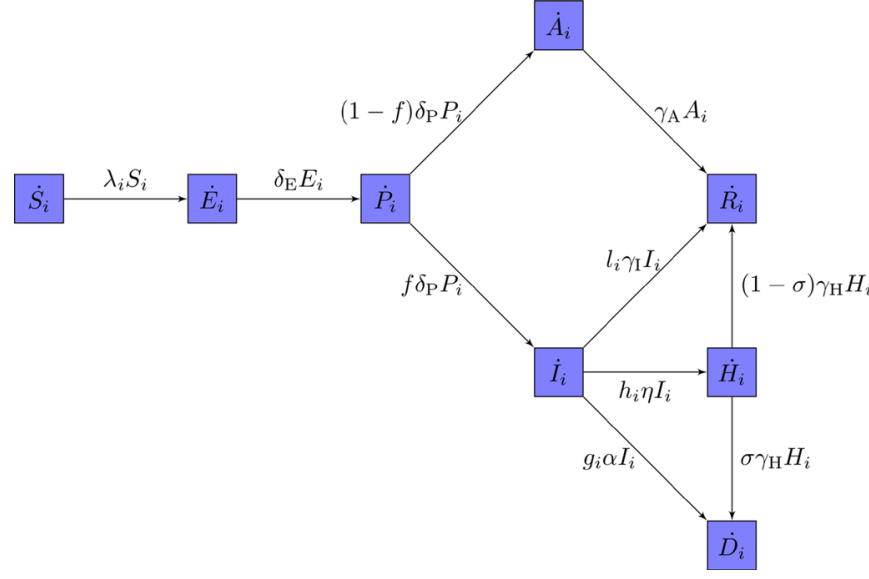

Figure 1 Diagram of the model. The model considers the following compartments: susceptible $(S)$ exposed $(E)$ infectious-presymptomatic $(P)$ infectious asymptomatic $(A)$ infectious symptomatic (I) infectious-requiring hospitalisation $(\mathrm{H})$ recovered $(\mathrm{R})$ and dead $(\mathrm{D})$.

only) effective way to minimise its spread, our models are of utmost importance for informing the implementation of realistic interventions in these regions.

\section{METHODS}

\section{The model}

We consider a model simulating a viral outbreak in a single camp over a 12-month period inspired by those proposed by Gatto et $a l^{10}$ and Bertuzzo et $a l^{13}$ (see figure 1). The model is adapted to the context of NWS IDP camps and is divided into compartments containing individuals at different possible stages along the disease's progression, governed by the following set of differential equations:

$$
\begin{gathered}
\dot{S}_{i}=-\lambda_{i} S_{i} \\
\dot{E}_{i}=\lambda_{i} S_{i}-\delta_{\mathrm{E}} E_{i} \\
\dot{P}_{i}=\delta_{\mathrm{E}} E_{i}-\delta_{\mathrm{P}} P_{i} \\
\dot{A}_{i}=(1-f) \delta_{\mathrm{P}} P_{i}-\gamma_{\mathrm{A}} A_{i} \\
\dot{I}_{i}=\delta_{\mathrm{P}} P_{i}-\left(l_{i} \gamma_{\mathrm{I}}+h_{i} \eta+g_{i} \alpha\right) I_{i} \\
\dot{H}_{i}=h_{i} \eta I_{i}-\gamma_{\mathrm{H}} H_{i} \\
\dot{R}_{i}=\gamma_{\mathrm{A}} A_{i}+l_{i} \gamma_{\mathrm{I}} I_{i}+(1-\sigma) \gamma_{\mathrm{H}} H_{i} \\
\dot{D}_{i}=g_{i} \alpha I_{i}+\sigma \gamma_{\mathrm{H}} H_{i}
\end{gathered}
$$

The susceptible population $\left(S_{i}\right)$ becomes exposed at rate $\lambda_{i}$, while exposed individuals $\left(E_{i}\right)$ progress through the latent period at rate $\delta_{\mathrm{E}}$ to a preclinical infectious stage $\left(P_{i}\right)$, which then progresses to (at rate $\delta_{\mathrm{P}}$ ) either a clinical (symptomatic, $I_{i}$, with probability $f$ ) or subclinical (asymptomatic, $A_{i}$, with probability $1-f$ ) infectious stage. Asymptomatic cases recover $\left(R_{i}\right)$ at rate $\gamma_{\mathrm{A}}$. Symptomatic cases have three potential outcomes: mild cases will recover at rate $\gamma_{\mathrm{I}}$, severe cases will progress to an 
Table 1 Fixed parameters

\begin{tabular}{|c|c|c|c|c|}
\hline Parameter & Description & Value & Distribution & Reference \\
\hline $1 / \delta_{E}+1 / \delta_{P}$ & Incubation period (days) & $5.2(95 \% \mathrm{Cl} 4.1$ to 7.0$)$ & Lognormal & 45 \\
\hline $1 / \delta_{P}$ & Presymptomatic infectious period (days) & $2.3(95 \% \mathrm{Cl} 0.8$ to 3.8$)$ & Gaussian & 1846 \\
\hline $1 / \delta_{E}$ & Latent period (days) & $\begin{array}{l}1 / \delta_{E}+1 / \delta_{P}-1 / \delta_{P} \\
\text { (Maximum }=0.5 \text { days) }\end{array}$ & & Derived \\
\hline $1 / \gamma_{1}$ & Symptomatic infectious period (days) & 7 & --- & 1847 \\
\hline $1 / \gamma_{A}$ & Asymptomatic infectious period (days) & 7 & --- & 1847 \\
\hline $1 / \eta$ & $\begin{array}{l}\text { Time from symptom onset to requiring } \\
\text { hospitalisation (days) }\end{array}$ & 7 (IQR: 4-8) & Gamma & 48 \\
\hline $1 / \alpha$ & $\begin{array}{l}\text { Time from symptoms onset to death (critical } \\
\text { cases, days) }\end{array}$ & 10 (IQR: 6-12) & Gamma & 48 \\
\hline $1 / \gamma_{H}$ & $\begin{array}{l}\text { Time from requiring hospitalisation to } \\
\text { recovery/death (days) }\end{array}$ & 10 (IQR: 7-14) & Gamma & 48 \\
\hline$f$ & $\begin{array}{l}\text { Probability an infectious individual is } \\
\text { symptomatic }\end{array}$ & $0.84(95 \% \mathrm{Cl} 0.8$ to 0.88$)$ & Gamma & 49 \\
\hline$\sigma$ & $\begin{array}{l}\text { Indicator of whether hospitalised recover or } \\
\text { die }\end{array}$ & $\sigma \in\{0,1\}$ & --- & Assumed \\
\hline
\end{tabular}

See online supplemental material for details.

extended infectious period during which they require hospitalisation $\left(H_{i}\right)$ at rate $\eta$, while critical cases requiring intensive care unit (ICU) care will die $\left(D_{i}\right)$ at rate $\alpha$. Finally, since the fate of individuals in the hospitalised compartment is uncertain if healthcare is not available, we run simulations considering two possibilities: either all recover $(\sigma=0)$, or all die $(\sigma=1)$ (see section Epidemiological severity assumptions). The specific values for the parameters are presented in table 1 .

While we introduced the model as a classical system of ordinary differential equations (Equations 1-8) we considered a stochastic implementation, ${ }^{14}$ with an integer description of the population in which a state is encoded in a vector $X=(S, E, P, I, A, H, R, D)^{t}$, with the total population size conserved throughout the simulation $N=S+$ $E+P+I+A+H+R+D$, where an arrow indicates transitions in which the source compartment transfers one individual to the target compartment. The mean transition rates corresponding to each transition are displayed. The system then evolves following a continuous-time Markov process which is simulated following the Gillespie algorithm implemented in the $\mathrm{R}$ package adaptivetau. ${ }^{15}$

\section{Demographic and behaviour classes}

The model splits the population into classes (indexed $i$ ) to account for heterogeneity with respect to clinical risk and behaviour. Working with population classes allows us to encode behavioural assumptions in the model and strike an appropriate balance between generality, computational tractability and the requisite specificity to realistically evaluate our proposed interventions. ${ }^{16}$ Moreover, the explicit representation of contacts between and within population classes allows us to design interventions considering cultural and context-specific assumptions (see section Interventions and online supplemental material for details). ${ }^{11}$ Under a null model where no interventions are implemented, the distinctions between classes are only dependent on age and comorbidity status (hereafter 'demographic classes'). $h_{i}, g_{i}$, and $l_{i}$ are demographic class-specific parameters, adjusted to ensure that the proportions of symptomatic cases progressing through each of the three potential clinical outcomes (mild, severe, and critical) are consistent with the literature (see section Epidemiological severity assumptions).

Under some interventions, the demographic classes may be subdivided further into subclasses according to behaviour ('behaviour classes'). Consequently, different interventions may require models with different numbers of classes. We refer to both demographic and behaviour classes generically as 'classes' (see section Interventions for the modelling of behaviour classes).

\section{Population structure and demographic classes}

We parameterised the model with data from IDPs in NWS. ${ }^{17}$ The population sizes of informal camps are rightskewed, with a mean of 1212 . We simulated camps with populations of 500, 1000 and 2000 individuals. Since interventions tend to be less effective in larger camps, the results presented refer to simulations with 2000 individuals, unless otherwise specified. For our demographic classes, we considered three age groups: children (age $1,0-12$ years old), younger adults (age $2,13-50$ years.) and older adults (age 3, $>50$ years.). For ages 2 and 3 , we considered two subclasses comprising healthy individuals and individuals with comorbidities (see table 2).

\section{Transmissibility assumptions}

Although individuals in IDP camps share tents with other co-occupants, whom they may be more likely to infect than occupants of different tents, we ignore spatial 
Table 2 Demographic class-specific parameters

\begin{tabular}{|c|c|c|c|c|c|c|c|}
\hline \multirow[b]{2}{*}{ Parameter } & \multirow[b]{2}{*}{ Description } & \multicolumn{6}{|c|}{ Demographic class } \\
\hline & & $\begin{array}{l}\text { Age } 1 \\
(0-12)\end{array}$ & $\begin{array}{l}\text { Age } 2 \\
(13-50) \text { no } \\
\text { comorbidities }\end{array}$ & $\begin{array}{l}\text { Age } 2 \\
(13-50) \\
\text { comorbidities }\end{array}$ & $\begin{array}{l}\text { Age } 3(>50) \text { no } \\
\text { comorbidities }\end{array}$ & $\begin{array}{l}\text { Age } 3(>50) \\
\text { comorbidities }\end{array}$ & References \\
\hline $\begin{array}{l}\text { Fraction in } \\
\text { class }\end{array}$ & - & 0.407 & 0.471 & 0.0626 & 0.022 & 0.0373 & 1750 \\
\hline$c_{i}$ & $\begin{array}{l}\text { Mean contacts } \\
\text { per day }\end{array}$ & 25 & 15 & 15 & 10 & 10 & $\begin{array}{l}\text { From camp } \\
\text { managers }\end{array}$ \\
\hline
\end{tabular}

Estimated proportions of individuals in the population and mean number of contacts per individual per day for each demographic class. See online supplemental materials for derivations.

structure in our model and assume a well-mixed population. This is justified because individuals from different tents share common spaces (e.g. latrines) and have frequent interactions with each other, especially among children. Consequently, our following derivation of the transmissivity parameter itself, $\tau$, is not spatially explicit.

The rate at which susceptible individuals become exposed is

$$
\lambda_{i}=\sum_{j=1}^{n} \tau C_{i j} \frac{\beta_{\mathrm{P}} P_{j}+\beta_{\mathrm{A}} A_{j}+\beta_{\mathrm{I}} I_{j}+\beta_{\mathrm{H}} H_{j}}{N_{j}}
$$

where $C_{i j}$ is the average number of contacts that individuals of class $i$ have with individuals of class $j$ per day and $N_{i}$ is the total population size of class $j$. We parameterised $C_{i j}$ by multiplying the mean number of total contacts that individuals from a population class $i$ have per day, $c_{i}$, by the probability of random interaction with individuals of class $j$. Considering a well-mixed population, this probability is proportional to class $j$ 's fraction of the total population, that is, $C_{i j}=c_{i} N_{j} / N$. If interventions are absent, we consider demographic classes only and, hence, different values of $c_{i}$ reflect heterogeneity in the number of contacts by demographic class. We assume specific values of $c_{i}$ for each class based on conversations with camp managers in NWS (see table 2).

The probability of infection if there is a contact between a susceptible and an infected person is $\tau \beta_{\mathrm{P}}, \tau \beta_{\mathrm{A}}, \tau \beta_{\mathrm{I}}$, or $\tau \beta_{\mathrm{H}}$ depending on whether the infected individual is in the presymptomatic $\left(P_{i}\right)$, symptomatic $\left(I_{i}\right)$, asymptomatic $\left(A_{i}\right.$ ) or hospitalised compartment $\left(H_{i}\right)$, respectively. The $\tau$ parameter represents the maximum transmissivity, which is observed at the presymptomatic stage for individuals who go on to become symptomatic. ${ }^{18}$ Thus, we selected the transmissivity of these individuals as a reference $\left(\beta_{\mathrm{P} \rightarrow 1}=1\right)$ with the remaining parameters set relative to $\beta_{\mathrm{P} \rightarrow \mathrm{I}}\left(\beta_{i}<\beta_{\mathrm{P} \rightarrow \mathrm{I}}, i \in\{\mathrm{P}, \mathrm{A}, \mathrm{H}, \mathrm{I}\}\right)$, where the mean transmissibility of all presymptomatic individuals $\left(\beta_{\mathrm{P}}\right)$ is estimated as a weighted average of the transmissibility of individuals that will become symptomatic and asymptomatic (see table 3, online supplemental materials for derivation).

The $\tau$ parameter was estimated by randomly generating a value for the basic reproduction number, $R_{0}$, following a Gaussian distribution with a mean of 4 (99\% CI 3 to 5 ) and dividing this value by the dominant eigenvalue of the next-generation matrix (see section Computational implementation for details and online supplemental material for the analytical results). The distribution of $R_{0}$ was a compromise between values reported in the literature from regions with high-density informal settlements: $R_{0}=2.77$ in Abuja and 3.44 in Lagos, Nigeria, ${ }^{19}$ 3.3 in Buenos Aires ${ }^{20}$ and 5 in Rohingya refugee camps in Bangladesh. ${ }^{21}$

Table 3 Transmissibility parameters

\begin{tabular}{|c|c|c|c|c|}
\hline Parameter & Description & Value & Distribution & Reference \\
\hline$\tau$ & Maximum transmissibility & $0.14(95 \% \mathrm{Cl} 0.05$ to 0.40$)$ & Lognormal & Derived \\
\hline$\beta_{\mathrm{P} \rightarrow \mathrm{I}}$ & $\begin{array}{l}\text { Presymptomatic transmissibility of } \\
\text { individuals becoming symptomatic } \\
\text { relative to } \tau\end{array}$ & Reference stage $(=1)$ & - & 1846 \\
\hline$\beta_{\mathrm{P}}$ & $\begin{array}{l}\text { Mean presymptomatic } \\
\text { transmissibility relative to } \tau\end{array}$ & $0.93(95 \% \mathrm{Cl} 0.88$ to 0.99$)$ & Empirical & Derived \\
\hline$\beta_{\mathrm{A}}$ & $\begin{array}{l}\text { Asymptomatic transmissibility } \\
\text { relative to } \tau\end{array}$ & $0.14(95 \% \mathrm{Cl} 0.05$ to 0.40$)$ & Lognormal & Derived \\
\hline$\beta_{\mathrm{I}}$ & $\begin{array}{l}\text { Clinical symptomatic } \\
\text { transmissibility relative to } \tau\end{array}$ & 0.24 (95\% Cl 0.11 to 0.60$)$ & Lognormal & Derived \\
\hline$\beta_{\mathrm{H}}$ & $\begin{array}{l}\text { Hospitalised transmissibility } \\
\text { relative to } \tau\end{array}$ & $0.11(95 \% \mathrm{Cl} 0.05$ to 0.29$)$ & Lognormal & Derived \\
\hline
\end{tabular}

See online supplemental materials for details. 
Demographic class

\begin{tabular}{llcllll}
\cline { 3 - 6 } Parameter & Description & Age 1 (0-12) & $\begin{array}{l}\text { Age 2 } \\
(\mathbf{1 3 - 5 0 )} \text { no } \\
\text { comorbidities }\end{array}$ & $\begin{array}{l}\text { Age 2 (13-50) } \\
\text { comorbidities }\end{array}$ & $\begin{array}{l}\text { Age 3 } \\
(>50) \text { no } \\
\text { comorbidities }\end{array}$ & $\begin{array}{l}\text { Age 3 }(>50) \\
\text { comorbidities }\end{array}$ \\
\hline$q_{i}^{\mathrm{H}}\left(h_{i}\right)$ & $\begin{array}{l}\text { Fraction of } \\
\text { symptomatic } \\
\text { cases sever }\end{array}$ & $0.064(0.064)$ & $0.067(0.066)$ & $0.199(0.191)$ & $0.183(0.178)$ & $0.445(0.406)$ \\
\hline$q_{i}^{\mathrm{D}}\left(g_{i}\right)$ & $\begin{array}{l}\text { Fraction of } \\
\text { symptomatic } \\
\text { cases critical }\end{array}$ & $0.0065(0.009)$ & $0.020(0.028)$ & $0.094(0.129)$ & $0.063(0.088)$ & $0.222(0.289)$ \\
\hline
\end{tabular}

Since the rates at which these cases become severe, critical or recover are different, we introduced three parameters $\left(h_{i}, g_{i}\right.$ and $\left.l_{i}\right)$ to distribute individuals according to the desired proportions (values between parenthesis). The proportion of individuals recovering is computed as $1-q_{i}^{H}-q_{i}^{D}$ (see online supplemental materials for details).

\section{Epidemiological severity assumptions}

In NWS, there are four active and two planed COVID-19 referral hospitals, with a current capacity of 66 ventilators, 74 ICU beds and 355 ward beds for 4.2 million people. ${ }^{22} 23$ Estimations based on an exponential growth model from Hariri et al predicted a collapse of health facilities 8 weeks into an outbreak. ${ }^{24}$ Although we do not have access to official data on healthcare occupancy, the reported number of cases suggests that this scenario could have been reached. ${ }^{8}$ Hence, we considered a worst-case scenario in which individuals will not have access to healthcare and assumed that all critical cases (those requiring ICU care) would die. However, there is greater uncertainty about the fate of severe cases, those requiring hospitalisation but not ICU care. We therefore considered a compartment for severe cases to account for a longer infectious period if they stay in the camp (see compartment $H_{i}$, figure 1). This compartment also helped us model some interventions more realistically, for example, by noting that the symptoms of severe cases are incompatible with self-isolation. To estimate upper and lower bounds for the outcome variables of our model, we simulated two possible scenarios for the fate of this compartment: one in which all cases recover, and another in which all cases die. In the simulations presented in the Main Text, we consider the worst-case scenario in which all cases die.

The fractions of symptomatic cases that are severe $\left(q_{i}^{H}\right)$, critical $\left(q_{i}^{D}\right)$ and recover $\left(q_{i}^{R}\right.$, where $\left.q_{i}^{R}=1-q_{i}^{H}-q_{i}^{D}\right)$ are demographic class-specific (see table 4 ). We estimated the fractions of symptomatic cases in each demographic class that would become severe $\left(q_{i}^{\mathrm{H}}\right)$ and critical $\left(q_{i}^{\mathrm{D}}\right)$ using data from developed countries with superior population health. ${ }^{25}{ }^{26}$ Following previous work, ${ }^{12}$ we mapped the age-specific case severity distributions of the NW Syrian adult population to those of age groups 10 years older in developed countries.

Since the rates at which clinical symptomatic individuals $\left(I_{i}\right)$ resolve into these three epidemiological outcomes are different ( $\eta$ for $H, \alpha$ for $D$ and $\gamma_{\mathrm{I}}$ for $R$ ) we introduced three parameters, $h_{i}, g_{i}$ and $l_{i}$, to distribute individuals according to the desired proportions. The analytic derivation is provided in online supplemental material and the specific values in table 4 .

\section{Interventions}

The interventions we consider are modelled by modifying the rate at which individuals become exposed (the term $\lambda_{i}$, Eq. 9), and/or adding new population classes that govern behavioural changes (behaviour classes). Since $\lambda_{i}$ can be factorised in four terms, the interventions may influence one or several of these terms. The factors present in $\lambda_{i}$ and the terms modulating them in the interventions are (see Eq. 10): (1) the maximum transmissibility, $\tau$, which is reduced in some interventions by a factor $\xi_{i j}$, when interactions are restricted to buffer zones (see below for details); (2) the average number of contacts that individuals in class $i$ have per day, $c_{i}$. This quantity can either be uniformly reduced across all classes, or the contact rate of class $i$ with class $j$ can be modified. We model this modification of contact rates using the matrix $\epsilon_{i j}$; (3) the probability of encounter between members of class $i$ and $j$ in a well-mixed population, $N_{j}=N$. This probability can vary by modifying the visibility of a member of class $j$ to a member of class $i$, which we express with the matrix $\omega_{i j}$ and (4) the probability of becoming infected by individuals at specific stages of the disease (eg, for hospitalised individuals this is encoded in the term $\beta_{H} H_{j} / N_{j}$ ) which can be modified by specific factors. Only the terms for individuals at the clinical symptomatic $(I)$ and hospitalised $(H)$ stages are modified in our interventions, through the parameters $\zeta_{\mathrm{I}}$ and $\zeta_{\mathrm{H}}$, respectively. Following these considerations, the generic form of $\lambda_{i}$ under the interventions becomes:

$$
\lambda_{i}=\sum_{j=1}^{n} \underbrace{\tau \xi_{i j}}_{i} \underbrace{c_{i} \epsilon_{i j}}_{i i} \underbrace{\omega_{i j} \frac{N_{i}}{N}}_{i i i} \underbrace{\frac{\left(\beta_{P} P_{j}+\beta_{A} A_{j}+\zeta_{I} \beta_{I} I_{j}+\zeta_{H} \beta_{H} H_{j}\right)}{N_{j}}}_{i v}
$$

All interventions, self-distancing (see figure 2-1), selfisolation (see figure 2-2), safety zone (see figure 2-3) and evacuation (see figure 2-4) can be parameterised following this expression. The specific values of the parameters are presented in table 5 and their derivations in online supplemental materials. 


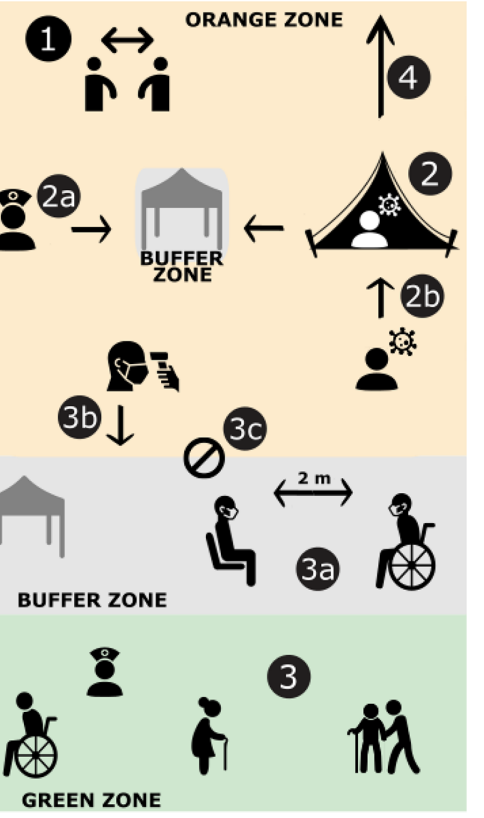

\begin{tabular}{|c|c|}
\hline Intervention/Description & Levels/Effect \\
\hline $\begin{array}{l}\text { 1. Self-distancing: reduction of mean number of } \\
\text { contacts per day per individual }\end{array}$ & $10 \%, 20 \%, 30 \%, 40 \%, 50 \%$ \\
\hline $\begin{array}{l}\text { 2. Self-isolation } \\
\text { Isolation of symptomatic people in individual tents }\end{array}$ & $\begin{array}{l}\text { Number of available tents: } 10,20,50,100, \\
250,500,1000,2000\end{array}$ \\
\hline $\begin{array}{l}\text { 2a. Number of carers: number of healthy people } \\
\text { that will take care of self-isolated people }\end{array}$ & 1 per tent \\
\hline $\begin{array}{l}\text { 2b. Self-isolation delay: time from symptom onset } \\
\text { to self-isolation }\end{array}$ & $12 h, 24 h, 48 h$ \\
\hline $\begin{array}{l}\text { 3. Safety zone } \\
\text { Designated area for vulnerable population }\end{array}$ & $\begin{array}{l}\text { Older adults only, } \\
\text { Older adults + adults with comorbidities, } \\
\text { Older adults + adults with comorbidities + } \\
\text { healthy adults and kids, up to } 20 \%, 25 \% \text {, or } \\
30 \% \text { of the population }\end{array}$ \\
\hline $\begin{array}{l}\text { 3a. Number of contacts people in the safety zone } \\
\text { can have with people from the exposed zone } \\
\text { (contacts always happen in the buffer zone) }\end{array}$ & $\begin{array}{l}2 \text { or } 10 \text { contacts per week per individual } \\
\text { residing in the safety zone }\end{array}$ \\
\hline 3b. Health checks & $\begin{array}{l}\text { Exclude symptomatic people from meeting } \\
\text { with people from the safety zone }\end{array}$ \\
\hline $\begin{array}{l}\text { 3c. Lockdown of safety zone if one case is detected } \\
\text { in the exposed zone }\end{array}$ & Reduces value of $3 a$ by $50 \%$, or $90 \%$ \\
\hline 4. Evacuation of severely symptomatic & $\begin{array}{l}\text { Evacuated individuals cannot infect other } \\
\text { people from the camp, but they do not } \\
\text { receive healthcare }\end{array}$ \\
\hline $\begin{array}{l}\text { Buffer zones } \\
\text { Open space, } 2 m \text { distancing, use of face cover }\end{array}$ & Reduces probability of infection by $80 \%$ \\
\hline
\end{tabular}

Figure 2 Diagram of interventions.

\section{Self-distancing}

The first non-medical intervention that we modelled is a reduction in the mean number of contacts per individual per day for the whole camp population (see figure 2-1). The average number of contacts of each class $c_{i}$ (see table 2) is reduced by a class-independent factor, hence the matrix $\epsilon_{i j}$ is uniform for all classes, that is, $\epsilon_{i j}=\epsilon, \epsilon \in\{0.9,0.8,0.7,0.6,0.5\}$. No further adjustments are required for this intervention. Since the mean number of inhabitants per tent in a camp is 5.5 and sanitation facilities are shared, ${ }^{17}$ we inferred that the number of contacts per day cannot be reduced by more than $50 \%(\epsilon=0.5)$. For a younger adult, this would mean 7.5 contacts per day.

\section{Self-isolation}

Self-isolation is a challenge in informal settlements, where households consist of a single (often small) space, water is collected at designated locations, sanitation facilities are communal and food supplies are scarce. We considered the possibility of those showing symptoms (i.e. in compartment I) self-isolating in individual tents in dedicated parts of the camps. We excluded individuals with severe symptoms (H compartment) from the intervention since they require additional care not compatible with self-isolation. Instead, we considered the possibility of evacuating these individuals from the camp as an additional intervention (see below). We simulated self-isolation with various numbers of isolation tents per camp, ranging from 10 to 2000 for a camp of 2000 people (see figure 2-2a). In addition, we modelled the role of carers dedicated to providing for isolated individuals (see figure 2-2a). Carers are drawn from the younger adults' class with no comorbidities who are not at a stage of the disease during which they display symptoms (i.e. not in compartments I or $\mathrm{H}$ ), while isolated individuals may belong to any class. Since this intervention only modifies the infectiousness of individuals in the I compartment and the exposure of carers, the consideration of additional behavioural classes is not required. Instead, the intervention can be encoded in $\lambda_{i}$ by simply splitting the contribution of symptomatic individuals to the rate of exposure into two terms, one for the isolated individuals and another for the remaining population. Hence, its implementation requires deriving the parameters $\epsilon_{i j}$ and $\omega_{i j}$ for interaction between healthy younger adults (from which carers are drawn), the remaining classes, and isolated and non-isolated individuals separately. In table 5, we present these terms and their derivation in online supplemental materials.

In addition, interactions between carers and isolated individuals were restricted to buffer zones, which we envisioned as open spaces, with guidelines in place to limit occupancy to four individuals wearing masks with at least $2 \mathrm{~m}$ of distance between them, where we assume transmissivity is reduced by $80 \%\left(\xi_{i j}=0.2\right)$. In considering one carer per isolated individual with one contact per day, we do not neglect their probability of infecting the rest of the camp.

\section{Safety zone}

In this intervention, the camp is divided in two areas: a safety zone, in which more vulnerable people live (hereby referred to as a 'green' zone following previous studies), ${ }^{12}$ and an exposed ('orange') zone with the remaining population. In our simulations, the first exposed individual always belongs to the orange zone. The living conditions within both zones remain the same, so the overall contact rate does not change unless self-distancing is also implemented. A consequence of maintaining the overall contact rate is that reducing contacts with individuals living in a different zone implies an increase in 


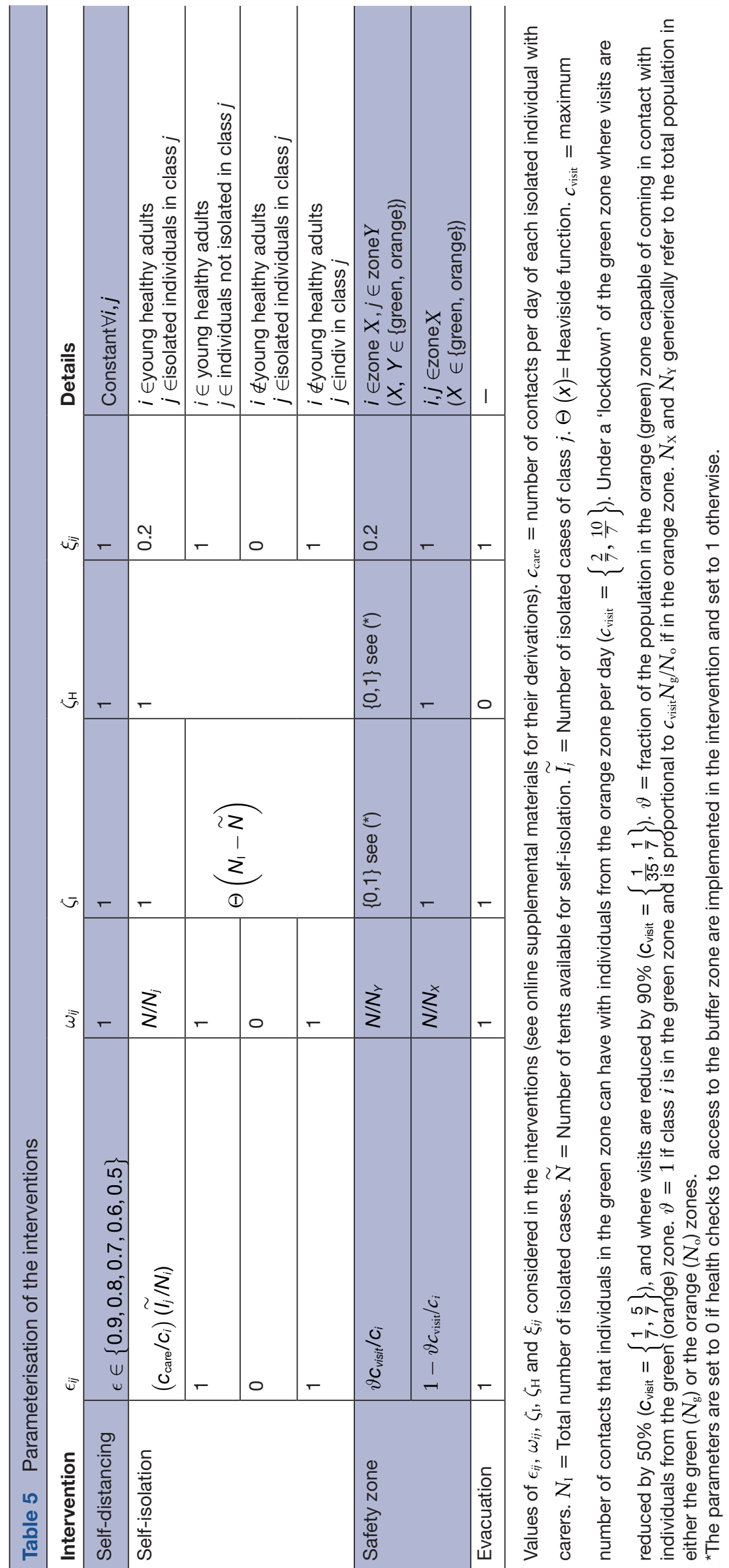


contacts with individuals in the same zone (see online supplemental material). Although we do not expect this assumption to be true in general, it allows us to investigate undesired side effects of this intervention, such as older adults having increased contacts among themselves if isolated together. Since proposals for partitioning the population may be received differently across camps, we considered several scenarios for allocating a camp population to the two zones (see figure 2-3). Implementing this intervention thus requires the split of some demographic classes into two behaviour classes, depending on the scenario. For example, if some healthy younger adults are allocated into the green zone, we split the demographic class 'healthy younger adults' into 'orange' and 'green' behaviour classes, to model the different contact rates that these two subclasses of healthy younger adults will have among themselves and with other classes. In online supplemental table 2, we present the classes considered in each scenario.

Interactions between the two zones are limited to a buffer zone, reducing transmissivity (i.e. $\xi_{i j}=0.2$, see previous section). Individuals in the green zone cannot leave and thus need to be provided with supplies by individuals in the orange zone, which will take place in the buffer zone. In our simulations, we considered limiting individuals in the green zone to 10 or 2 contacts with individuals from the orange zone per week (see figure 2-3a). Other variations of this intervention we explored include preventing symptomatic individuals from entering the buffer zone (incorporating health checks, see figure 2-3b) and a 'lockdown' of the green zone, where the number of weekly contacts in the buffer zone is reduced by $50 \%$ or $90 \%$ (see figure 2-3c). Although overall contact rates are conserved in this intervention, we modify the contact rates between $i$ and $j$ with $\epsilon_{i j}$ and the probability of interaction between $i$ and $j$ with $\omega_{i j}$, where both parameters are determined by whether $i$ and $j$ are in the same or different zones (see table 5 for specific values and online supplemental materials for derivation).

\section{Evacuation}

The last intervention we simulated is the evacuation of severe cases (individuals in the hospitalisation compartment). Since they require more intensive care that cannot be delivered while adhering to the guidelines of a buffer zone, severe cases were assumed to be fully infectious and not able to self-isolate. Once severe cases are evacuated, their infectivity is reduced to zero $\left(\zeta_{\mathrm{H}}=0\right.$, see figure $\left.2-4\right)$. The fate of severe cases is not altered by this intervention since we assumed that hospitals are saturated and that evacuees are transferred to isolation centres instead.

\section{Computational implementation and statistical analysis}

The specific values of the parameters shown in Eqs. 1-8 and of $R_{0}$ are independently drawn at each integration step from the probability distributions shown in tables 1, 3 and 4. We note that by generating transition rates from the empirically determined residence times, we are not reproducing these residence times for the simulated individuals. In our simulations, individuals will experience exponentially-distributed residence times with a mean equal to the mean of the correspondent distribution (to $1 / \kappa$ in the case of the symptomatic compartment, see online supplemental material 1 for the definition of $\kappa$ ). The generation of random values around the mean following the empirical distribution at each time step is aimed at adding noise to the mean, to partially account for the empirical uncertainty.

The next-generation matrix is also computed at each integration step from the parameters drawn and $\tau$ estimated. In the code provided, it is possible to fix the seed to exactly reproduce the results presented. Our simulations start with a completely susceptible population where one person in the younger adult population is exposed to the virus (who is also in the orange zone if the safety zone intervention is in place). We verified that a steady state was always reached before the end of each simulation. We did not consider migration, births, nor deaths due to other causes, since they are small enough in magnitude to not significantly impact the course of an outbreak, provided additional conflict does not erupt.

For each implementation of the interventions, we ran 2500 simulations and compared results between them. The main variables considered are the fraction of simulations in which at least one death is observed (a proxy for the probability of an outbreak), the fraction of the population that dies and the time until the symptomatic population peaks, as well as the infection fatality rate (IFR), and the fractions of the population that have recovered and remain susceptible at steady state. For consistency, we only considered simulations in which there was an outbreak when comparing the outcome of a variable between interventions. We used the Shapiro-Wilk test ${ }^{27}$ to verify that our results do not exhibit normally distributed residuals, and Conover-Iman test for multiple comparisons. ${ }^{28}$ We used the R package PMCMRplus. ${ }^{29}$ Confidence intervals for the probability of outbreak were computed with Wilson's method ${ }^{30}$ implemented in the $\mathrm{R}$ package binom. ${ }^{31}$ The model and all statistical analyses were implemented in $\mathbf{R}^{32}$

\section{RESULTS}

In the absence of interventions, the mean IFR is $\sim 2.5 \%$ in simulations where all severe cases requiring hospitalisation recover (see online supplemental figure 1), and $\sim 11 \%$ in simulations where all severe cases die. We consider the latter scenario to evaluate the effect of nonmedical preventive interventions. In this scenario, the probability of observing an outbreak is close to 0.84 , in which $\gtrsim 10 \%$ of the camp dies, the number of symptomatic cases peaks after 40 days, $\sim 84 \%$ of the population recovers, and $\sim 5 \%$ remain susceptible.

\section{Self-distancing}

Our results show that self-distancing has a notable effect on reducing the probability of an outbreak which decreases roughly linearly as the number of contacts 

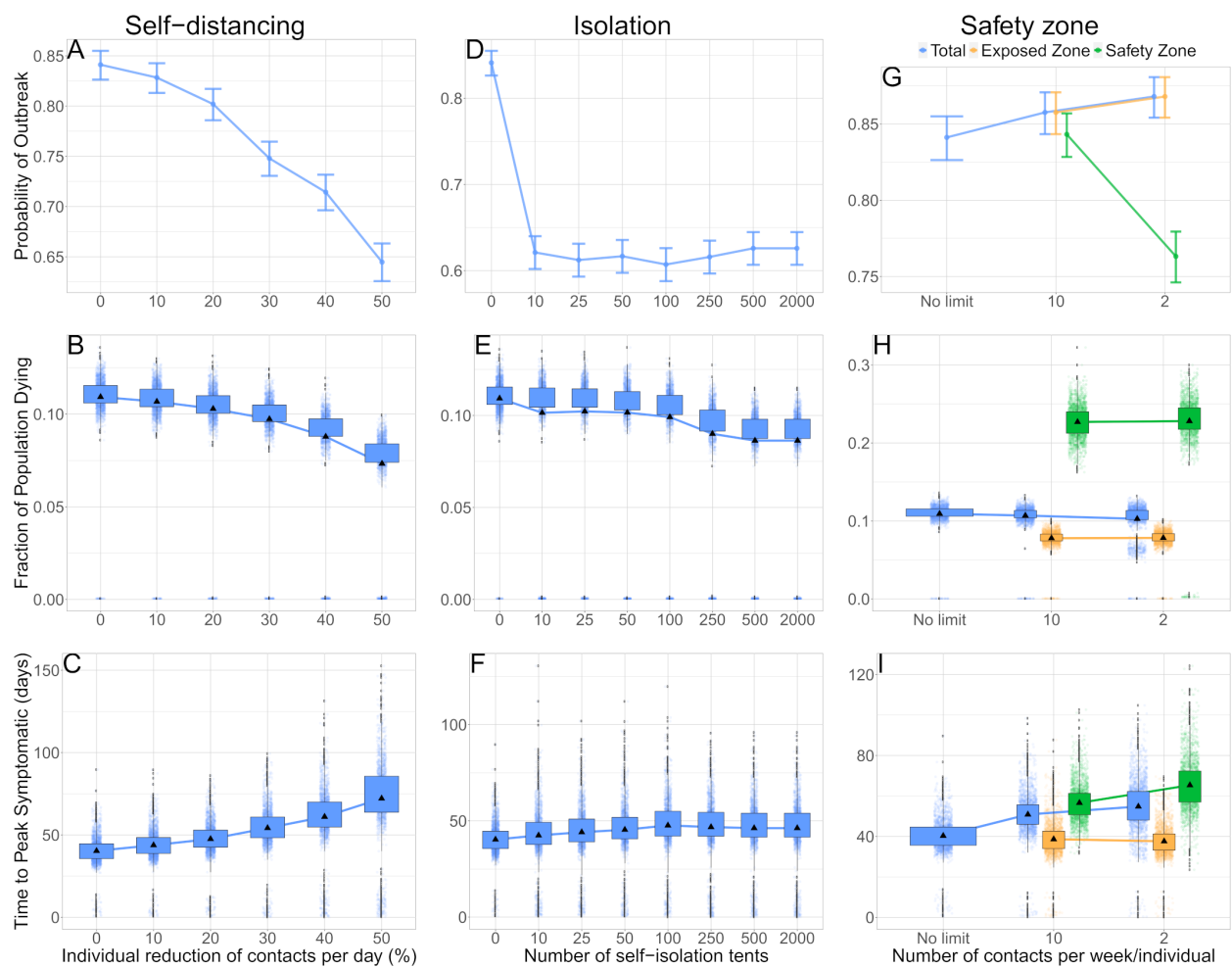

Figure 3 Effect of interventions on outbreak probability, fatalities and time until symptomatic cases peak. (A) Self-distancing, probability of an outbreak. (B) Self-distancing, fraction of the population dying. (C) Self-distancing, time until peak symptomatic cases. (D) Self-isolation, probability of an outbreak. (E) Self-isolation, fraction of the population dying. (F) Self-isolation, time until peak symptomatic cases. (G) Safety zone, probability of an outbreak. (H) Safety zone, fraction of the population dying. (I) Safety zone, time until peak symptomatic cases. Triangles indicate the means and boxes IQRs. Note that in figures of the safety zone intervention (panels G-I), the mean of an outcome for the whole population is not the weighted mean of the exposed and safety zones, since outcomes are computed considering simulations in which at least one death was observed in the population class inhabiting the zone, that is, the number of simulations considered to compute each mean is different. In the safety zone figures (panels G-l) health checks are in place, in online supplemental figure 5) we show the effect of removing health checks.

is reduced (see figure 3A). A near-quadratic trend is observed for the fraction of the population dying, with a greater decrease for larger reduction in daily contacts, achieving a $34 \%$ reduction in mortality when the number of contacts is reduced by $50 \%$ (see figure $3 \mathrm{~B}$ ). Selfdistancing also significantly extends the time until the peak of the outbreak, from $\sim 40 \%$ days when no interventions are in place to 72 days when contacts are reduced by $50 \%$ (see figure $3 \mathrm{C}$ ). The proportion of the population remaining susceptible after 12 months also increases to nearly $33 \%$ when a $50 \%$ reduction is considered, and the proportion of the population recovered after 12 months (which informs on the potential population level protection against future outbreaks) is reduced from $84 \%$ to $60 \%$ (see online supplemental figure 2).

\section{Self-isolation}

With only 10 tents for a camp of 2000 people (i.e. 1 tent for every 200 people), self-isolation yields a marked decrease in the probability of observing an outbreak $(\sim 26 \%)$ (see figure 3D) and a low decrease in mortality ( 7\%) (see figure $3 \mathrm{E}$ ), suggesting that with a low number of tents the intervention is mostly effective at isolating index cases and preventing the epidemic from starting. In order to observe a greater mortality reduction $(\sim 18 \%)$ and an increase in time $(\sim 6 \%)$ until the number of symptomatic cases peaks, further increasing the number of tents up to at least one tent for every eight people is required. Increasing the number of tents does not further reduce the probability of observing an outbreak. There is also an increase in the number of susceptible individuals at the end of the simulation when the number of tents is increased. We finally observed an artificial increase in the IFR explained by an increasingly large number of simulations in which very few individuals are infected since, if at least one of them dies, we obtain a high IFR value (see online supplemental figure 3 ).

\section{Evacuation}

We observe no significant effects when severe cases requiring hospitalisation are evacuated (see online supplemental figure 4). Since we considered that these individuals will not receive healthcare (they are evacuated to isolation centres), their fate remains the same as if they were to stay in the camp. Hence, we expect evacuation to only have an effect on their infectivity. Although these individuals are infectious for a longer period of time than those with milder symptoms ( $\sim 10$ days longer $)$, the 
number of individuals under these conditions is only a small fraction of the total infectious population at any given time, explaining why we do not observe significant effects for this intervention.

\section{Safety zone}

In this section, we consider the scenario in which all older adults, younger adults with comorbidities and their family members up to $20 \%$ of the camp population live in the green zone, unless otherwise specified. Creating a green zone improves the effect of the previous interventions overall, but with sometimes opposite outcomes in the exposed and protected populations. For example, the probability of an outbreak decreases for the protected population, by around $11 \%$, if only two contacts are allowed per week in the buffer zone (see figure 3G). Notably, most of this reduction is only achieved when health checks excluding symptomatic individuals from the buffer zone are in place (see online supplemental figure 5 for the effect of removing health-checks). On the other hand, the probability of an outbreak may slightly increase for the exposed population, a consequence of the relative increase in intra-zone contacts. By shifting the burden of an outbreak towards the less vulnerable population in the orange zone, another important outcome of this intervention is the notable increase in time $(62 \%)$ until the number of symptomatic cases peaks for the vulnerable population, and a $36 \%$ increase in time for the whole population (see figure 3I). Nevertheless, this intervention only has a modest reduction on overall mortality (see figure $3 \mathrm{H}$ and online supplemental figures 6 and 7), possibly due to the high infectiousness of presymptomatic individuals.

Considering different scenarios for allocating people to the green zone, the lowest probability of an outbreak is achieved when only older adults or at most older adults and younger adults with comorbidities move there, with probabilities below 0.4 and 0.65 , respectively (see online supplemental figure 8 ). Positive effects of the safety zone intervention are even more marked in camps with smaller populations, especially for probability of an outbreak in the green zone (which decreases by 55\%) and overall mortality (which decreases by $20 \%$ ) when the population is reduced from 2000 to 500 . However, we also observe the adverse effect of a decrease in time until symptomatic cases peak (see online supplemental figure 9). The incorporation of a lockdown has the greatest effect on reducing the probability of an outbreak in the green zone, to under 0.25 when contacts in the buffer zone are reduced by $90 \%$. While lockdowns show no positive effect on green zone fatalities in the few instances where an outbreak does reach there, they decrease overall IFR and fatalities by further concentrating outbreaks in the less vulnerable population (see online supplemental figure $10)$.

\section{Combined interventions}

The effects of the interventions observed when we examine them individually build on each other when multiple interventions are implemented in tandem (see figure 4 and online supplemental figure 11). The protective effects of the safety zone intervention are most fully realised when paired with other interventions. They become so effective that outbreaks in the green zone become exceptionally rare, but so well controlled when they do happen, that the majority of outbreaks are small enough for us to observe an anomalous increase in IFR in some of the most effective interventions, driven by the discretisation of the values it can take (e.g. if there is only one case and this person dies, see online supplemental table 13). When all interventions are implemented together: strict self-distancing $(50 \%$ reduction in contacts), self-isolation of symptomatic cases (1 tent for every 40 people), a safety zone with 2 contacts per week in the buffer zone, health checks, a strict lockdown $(90 \%)$ and evacuation of severe cases, mortality is reduced by $\sim 94 \%$ and the probability of outbreak in the green zone is very small $(\sim 0.005)$. In other combinations with a higher probability of outbreak (e.g. considering in the previous combination a $20 \%$ reduction in contacts instead of $50 \%$ ) the time to peak of symptomatic cases in the green zone is delayed by 48 days.

\section{DISCUSSION}

In this study, we propose a number of interventions of immediate applicability to informal settlements. We focused on IDP settlements in NW Syria, taking into account the interventions' feasibility, cultural acceptance and their need for low cost. When confronted with different possible scenarios, we generally considered the worst-cases, highlighting the interventions that are most effective in the direst conditions, but possibly resulting in an overestimate of mortality. This potential overestimation does not change the qualitative picture of the results, which is built on the relative comparison of outcomes between different combinations of interventions, or the lack thereof.

Our results align with previous simulation studies of potential COVID-19 interventions in similarly densely populated, low-resource settings where informal settlements are present, such as urban areas of sub-Saharan Africa. In these settings, social distancing is demonstrated to be an effective intervention, and even small changes are estimated to have large effects on outbreaks, ${ }^{33}$ in some cases determining whether or not already inadequate healthcare systems become overwhelmed. ${ }^{34}$ van Zandvoort et al show that similar measures to the ones we consider-self-isolation, physical distancing and 'shielding' the vulnerable-may reduce mortality by $60 \%-75 \%$ in African cities. ${ }^{12}$

Self-distancing proves to be an effective measure in our models as well; reducing contacts by $50 \%$ has the greatest effect across most outcomes of interest in any of the interventions we examined. However, the difficulty of achieving a reduction of this magnitude cannot be overlooked, especially considering the large proportion 

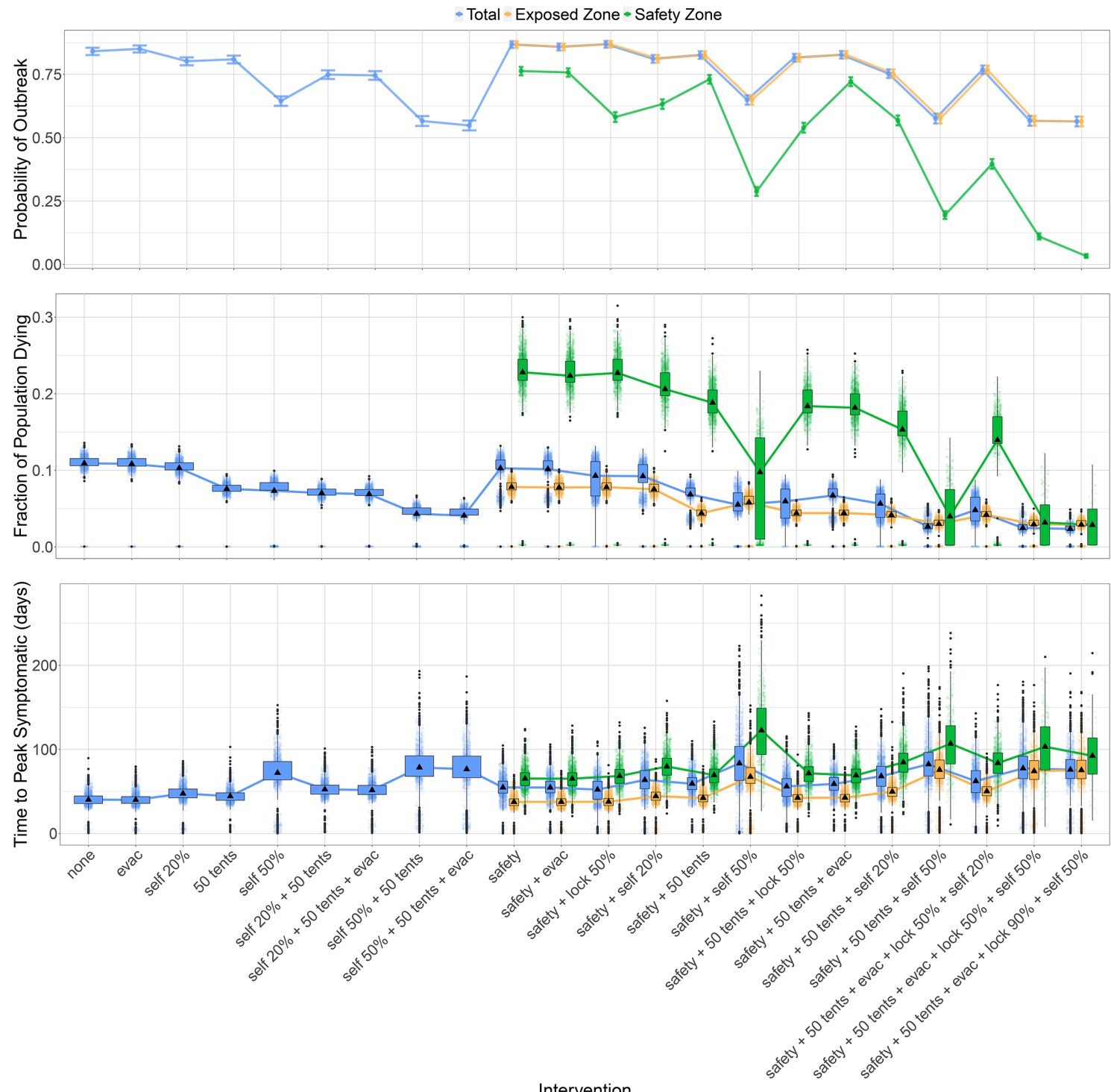

Figure 4 Combinations of interventions. Probability of an outbreak (top), fraction of the population dying (middle) and time until peak symptomatic cases (bottom) for different combination of interventions. For combinations of interventions including a safety zone, we distinguish between the population living in the green zone, in the orange zone and the whole population. Evac = evacuation of severely symptomatic; lock = lockdown of the buffer zone; safety = safety zone; self = self-distancing; tents = number of available self-isolation tents.

of the population composed of children, a group with an already high contact rate that may prove difficult to control. ${ }^{17}$ To illustrate the microdynamics of this intervention, in online supplemental figure 12, we plot the maximum proportion of the population exposed at any given point in time in each simulation, against the time it takes for symptomatic cases to peak. We observe that until reaching approximately $60 \%$, successive reductions in contacts reduce the maximum proportion of the population exposed while increasing the time until symptomatic cases peak. Additional reductions in contacts beyond $60 \%$ however abruptly decrease both the time until cases peak and overall mortality, suggesting that outbreaks die out before the virus spreads widely throughout the camp's population. This suggests the existence of a critical threshold for the number of individuals exposed over which large outbreaks become established in the population, significantly increasing mortality.

We also propose self-isolation using individual tents which can be located in a dedicated zone or next to the tents of relatives, where contact with non-isolated individuals is mediated by a buffer zone. This intervention is effective in preventing an outbreak in the camp with even a small number of isolation tents, as low as $5-10$ tents per 1000 camp residents. But it requires at least 125 tents per 1000 camp residents to substantially reduce mortality. After conversations with camp managers, we found that this intervention is more likely to be accepted in NW Syria than evacuation to community-based isolation centres. Community-based isolation not only poses cultural challenges; the capacity required to implement it has hardly been met, ${ }^{23}$ and it is still one of the main challenges in 
the region. ${ }^{8}$ We note that in our simulated intervention individuals become isolated as soon as they have symptoms. Recognising symptoms, however, may require some time and we should expect this intervention to be less effective unless systematic checks for symptomatic individuals are put in place.

Setting up a safety zone has two positive effects that most stand out: a reduction in the probability of an outbreak in the vulnerable population, and an increase in the time until the number of symptomatic cases peaks. Much of the success or failure of the safety zone intervention hinges on the functioning of the buffer zone. The number of interzone contacts per week, the implementation of health checks, and potential lockdowns all have notable effects. Also important is the portion of the population that is protected; protecting only the vulnerable may have the most beneficial effects, but it is precisely these vulnerable individuals, older adults, and people with comorbidities, who may most need family members to care for them. While safety zone scenarios with more family members accompanying their vulnerable relatives may confer greater epidemiological risk, they may also engender greater well-being and social cohesion.

Despite these benefits, we do not observe a clear decrease in IFR with this intervention, although it is possible that our model may overestimate mortality from an outbreak in the green zone in the few instances when there is one. Since it is unlikely that the camps have the economic means to increase the number of tents when implementing this intervention, we assumed that individuals do not reduce their contacts when moved to the green zone since household sizes will not decrease, which implies an increase in the number of contacts between vulnerable individuals. Despite this increase in contacts, we do not observe an increase in mortality in the vulnerable population when the safety zone is implemented. These results address concerns raised around this type of intervention from previous experiences with large numbers of fatalities registered in nursing-homes in developed countries. ${ }^{35}$ While nursing-homes in developed countries may be seen as analogous to the safety zone intervention, the alternative to nursing homes in developed countries for the elderly population typically involves remaining at home with few contacts with younger individuals (in a scenario of lockdown), while in the camps the alternative is living in tents shared with younger individuals with high contacts rates (especially children). This may explain why we observe a positive effect from this intervention despite a relative increase in contacts among the most vulnerable subpopulation.

An instrumental consideration for our models is the fraction of the population recovered from COVID-19 after a steady state is reached. Although the duration for which SARS-CoV-2 infection confers immunity is uncertain, the proportion of the population recovered after an outbreak should play a role in its protection against future ones. For all interventions except self-distancing
$>30 \%$, we observed that the fraction of the population recovered meets or exceeds $50 \%$.

Other important considerations for interpreting our results are the modelling assumptions we made. One important parameter in our model is the relative transmissibility of the different infectious stages, whose specific values still have large margins of variability. ${ }^{18337}$ This is particularly relevant for non-medical interventions that rely on the identification of symptomatic individuals because the higher the relative infectivity of presymptomatic and symptomatic individuals, the lower the effectiveness of such interventions. For instance, Bullock et al assumed a higher infectiousness of the presymptomatic stage and hence self-isolation of symptomatic individuals had little effect. ${ }^{38}$ Self-isolation also becomes ineffective under the assumptions made by Hernandez-Suarez et al when they considered isolating only severe symptomatic cases (whose fraction is small), hence mildly symptomatic individuals were effectively considered asymptomatic. ${ }^{39}$ On the other hand, Gilman et al showed that self-isolation was effective when considering individuals at different stages to be equally infectious. ${ }^{40}$ We assumed that presymptomatic individuals have the highest relative infectivity, consistent with the most recent estimations, ${ }^{37}$ and the interventions we proposed are still effective. Considering a different scenario in which all compartments are assumed to be equally infectious, our interventions become even more effective (see previous version of our manuscript). ${ }^{41}$

It is also important to acknowledge the benefits and limitations of different possible computational implementations. For instance, there are interventions that do not have a natural implementation within our framework, such as those requiring interventions targeting very specific interactions between individuals (as opposed to large groups of individuals), or the reproduction of empirically observed residence times. An example might be the isolation of an individual and his/her family, as proposed by Gilman et $a l^{40}$ which, since we do not explicitly model interactions at the family level, would require the creation of as many classes as families. When this level of detail is required, individual based models (IBMs) may be more appropriate. ${ }^{38} 40$ However, IBMs require a rich amount of data for their parameterisation which, although increasingly available, is scarce for informal IDPs camps. Our framework is powerful enough to simulate a large number of scenarios with little computational cost, which would be an optimal strategy as a first approximation in the design of interventions to narrow down the most relevant scenarios (for a reference, in $<24$ hours with just 12 cores we model 75 scenarios requiring quarter million simulations). The scenarios selected could then be further investigated with more detailed interventions using IBMs, if data is available.

A key limitation of our approach is that it simulates an outbreak started by one infectious individual in a single camp with a closed population. We acknowledge that this approach does not fully capture the complexities of the NWS 
region, where IDPs live interspersed throughout the region in several hundred camps. The dynamics of an outbreak in the region are undoubtedly influenced by inter-community contacts, and the dynamics of an outbreak in a single camp by these region-wide dynamics, as it has been demonstrated in other countries. ${ }^{1042}$ We expect our results to be robust to changes in population, as long as these changes are relatively small compared to the total population size in the camp, implying sporadic inputs of infected individuals. This is the expected behaviour in informal IDP camps, which are often small and located in rural areas, where substantial population movements such as those observed in large camps, are infrequent. This fact, in addition to the relatively young population in IDP camps, may help limit the damage done by an outbreak, as observe in some rural areas in sub-Saharan Africa. ${ }^{43}$

Other unaccounted for social and cultural dynamics will undeniably complicate the feasibility of our proposed interventions. One example we have not addressed here is the unlikeliness of children under 13 self-isolating. Although the number of challenges to implementing our proposed interventions are potentially endless, the community-based nature of our approach may make it more robust to such challenges than approaches relying on healthcare system, which often depend on complex political decisions and may take years to build the required capacity for an effective response. If the dynamics of the virus are well understood by local communities and at least some of the interventions we propose are implemented, the impacts of COVID-19 can be mitigated even in an environment as challenging as NW Syria.

\section{CONCLUSION}

Given a rapidly changing environment and slow responses of local and international authorities in conflict regions where political control is disputed, with international authorities often leaving these communities aside in their priorities, ${ }^{44}$ empowering local communities themselves is perhaps the best, if not the only way, to help them avoid the worst consequences of the pandemic. Such an approach may achieve greater compliance with nonmedical interventions, especially where there is a mistrust of external authority. This not only applies to IDP camps in NW Syria, but more generally to refugee camps in conflict-torn regions, and potentially other informal settlements and vulnerable communities around the world: the low cost, effective interventions we present are feasible, needed and urgent.

\section{Author affiliations \\ 'Institute of Integrative Biology, ETH Zürich, Zurich, Switzerland \\ ${ }^{2}$ Office of Population Research, Princeton University, Princeton, New Jersey, USA \\ ${ }^{3}$ Princeton Environmental Institute, Princeton University, Princeton, New Jersey, USA \\ ${ }^{4}$ University of Sussex, Brighton, UK \\ ${ }^{5}$ Pax Syriana Foundation, La Valeta, Malta}

Twitter Jordan D Klein @J_D_Klein and Eduard Campillo-Funollet @ecam85

Acknowledgements We thank Crowdfight (www.crowdfight.org) for organizing this collaboration upon request from CS. We thank Judith Boumann for valuable contributions. We thank Peter Ashcroft, Juan Poyatos, Noreen Goldman, Burcu
Tepekule and members of Sebastian Bonhoeffer's and Bryan Grenfell's groups for useful discussions. We thank two anonymous reviewers who provided thoughtful and insightful comments that greatly improved our article.

Contributors All authors contributed to the conceptualisation. Design of the methodology: APG, EC-F, JV, JDK and CS. Formal analysis: APG, EC-F and JDK. Code development APG, EC-F and JDK. Conducted research: APG, EC-F, JV and JDK. Validate results: APG, EC-F, JDK, JV and CS. Contributed resources: APG, CS, EC-F, JDK and JV. Data curation: APG, JDK and EC-F. Visualisation: APG, EC-F, JDK and JV. Writing (original draft) APG, EC-F, and JDK. All authors contributed to the final version of the manuscript, and APG supervised the research.

Funding ECF's research is supported by Wellcome Trust grant 204833/Z/16/Z APG research is supported by the Simons Collaboration: Principles of Microbial Ecosystems (PriME), award number 542381.

Disclaimer These organisations had no role in study design, data collection, data analysis, data interpretation, or writing of the article.

Competing interests APG is a Board Member of crowdfight COVID19, an initiative from the scientific community to put all available resources at service of the fight against COVID-19. CS (coauthor) is a Board Member of the Pax Syriana Foundation, a non-profit organisation set up for social and philanthropic purposes including promoting and providing support and assistance to civilian aid projects in the fields of education, health,emergency assistance, psychological assistance and humanitarian aid for people affected by wars or humanitarian crises.

Patient consent for publication Not required.

Provenance and peer review Not commissioned; externally peer reviewed.

Data availability statement Data are available in a public, open access repository. All the code and results are freely available at the url https:// crowdfightcovid19.github.io/req-550-Syria/, with the release used in the article permanently stored in Zenodo at the url https://doi.org/10.5281/zenodo.5148880

Supplemental material This content has been supplied by the author(s). It has not been vetted by BMJ Publishing Group Limited (BMJ) and may not have been peer-reviewed. Any opinions or recommendations discussed are solely those of the author(s) and are not endorsed by BMJ. BMJ disclaims all liability and responsibility arising from any reliance placed on the content. Where the content includes any translated material, BMJ does not warrant the accuracy and reliability of the translations (including but not limited to local regulations, clinical guidelines, terminology, drug names and drug dosages), and is not responsible for any error and/or omissions arising from translation and adaptation or otherwise.

Open access This is an open access article distributed in accordance with the Creative Commons Attribution Non Commercial (CC BY-NC 4.0) license, which permits others to distribute, remix, adapt, build upon this work non-commercially, and license their derivative works on different terms, provided the original work is properly cited, appropriate credit is given, any changes made indicated, and the use is non-commercial. See: http://creativecommons.org/licenses/by-nc/4.0/.

\section{ORCID iDs}

Alberto Pascual-García http://orcid.org/0000-0002-8444-3196

Jordan D Klein http://orcid.org/0000-0001-5417-1647

Jennifer Villers http://orcid.org/0000-0003-3832-3481

Eduard Campillo-Funollet http://orcid.org/0000-0001-7021-1610

\section{REFERENCES}

1 Lau LS, Samari G, Moresky RT, et al. COVID-19 in humanitarian settings and lessons learned from past epidemics. Nat Med 2020;26:647-8.

2 Abbas M, Aloudat T, Bartolomei J, et al. Migrant and refugee populations: a public health and policy perspective on a continuing global crisis. Antimicrob Resist Infect Control 2018;7:113.

3 Hill PS, Mansoor GF, Claudio F. Conflict in least-developed countries: challenging the millennium development goals. Bull World Health Organ 2010;88:562.

4 Sahloul MZ, Monla-Hassan J, Sankari A, et al. War is the enemy of health. pulmonary, critical care, and sleep medicine in War-Torn Syria. Ann Am Thorac Soc 2016;13:147-55.

5 Sikder M, Daraz U, Lantagne D, et al. Water, sanitation, and hygiene access in southern Syria: analysis of survey data and recommendations for response. Confl Health 2018;12:17.

6 Wilkinson A, Ali $\mathrm{H}$, Bedford J, et al. Local response in health emergencies: key considerations for addressing the COVID-19 
pandemic in informal urban settlements. Environ Urban 2020;32:503-22.

7 Health Information Central Unit and Health Directorates. Capacity of health sector in North of Syria, 2020.

8 United Nations Office for the Coordination of Humanitarian Affairs. Recent developments in Northwest Syria. Situation report No. 21 - as of 20 october 2020. Available: https://www. humanitarianresponse.info/en/operations/stima/document/situationreport-21-recentdevelopments-northwest-syria-20-october-2020s [Accessed 13 Nov 2020].

9 REACH initiative. Syria: camps \& sites needs assessment Northwest Syria sub-district profiles \& comparative dashboard, January - February 2020. Available: https://reliefweb.int/report/ syrian-arab-republic/syriacamps- sites-needs-assessmentnorthwest-syria-sub-district-profiles

10 Gatto M, Bertuzzo E, Mari L, et al. Spread and dynamics of the COVID-19 epidemic in Italy: effects of emergency containment measures. Proc Natl Acad Sci U S A 2020;117:10484-91.

11 Rhodes T, Lancaster K, Lees S, et al. Modelling the pandemic: attuning models to their contexts. BMJ Glob Health 2020;5.

12 van Zandvoort K, Jarvis $\mathrm{Cl}$, Pearson $\mathrm{CAB}$, et al. Response strategies for COVID-19 epidemics in African settings: a mathematical modelling study. BMC Med 2020;18:324.

13 Bertuzzo E, Mari L, Pasetto D, et al. The geography of COVID-19 spread in Italy and implications for the relaxation of confinement measures. Nat Commun 2020;11:1-11.

14 Engbert R, Drepper FR. Chance and chaos in population biologyModels of recurrent epidemics and food chain dynamics. Chaos, Solitons \& Fractals 1994;4:1147-69.

15 Johnson P. Adaptivetau: tau-leaping stochastic simulation. 22-3. R package, 2019.

16 Funk S, Bansal S, Bauch CT, et al. Nine challenges in incorporating the dynamics of behaviour in infectious diseases models. Epidemics 2015;10:21-5.

17 Unit AC. The Syrian IDP camps monitoring study - Northern Syria camps - humanitarian data exchange. Available: https://data. humdata.org/dataset/idp-camps-monitoring-november-of-2018

$18 \mathrm{He}$ X, Lau EHY, Wu P, et al. Temporal dynamics in viral shedding and transmissibility of COVID-19. Nat Med 2020;26:672-5.

19 Oyinlola MA, Osayomi T, Adeniyi O. Empirical modelling of confirmed Covid-19. Cases in Nigeria: Forecasts and Implications, 2020.

20 Santos JE, Carcione JM, Savioli GB. A numerical simulation of the COVID-19 epidemic in Argentina using the SEIR model. arXiv preprint arXiv 2020.

21 Truelove S, Abrahim O, Altare C, et al. The potential impact of COVID-19 in refugee camps in Bangladesh and beyond: A modeling study. PLoS Med 2020;17:e1003144.

22 REACH initiative.. North West Syria situation overview, (16 March 2020). Available: https://www.impactrepository. org/document/ reach/0169bf6a/REACH SYR Situation-Overview Northwest-Syria 16-March-2020-1.pdf

23 United Nations Office for the Coordination of Humanitarian Affairs. Recent developments in Northwest Syria. S ituation report no. 19 - as of 21 august 2020. Available: https://reliefweb.int/report/syrianarab-republic/recentdevelopments- northwest-syria-situation-reportno-19-21-august [Accessed 24 Aug 2020].

24 Hariri M, Rihawi H, Safadi S. The Covid-19 forecast in northwest Syria the imperative of global action to avoid catastrophe. medRxiv 2020.

25 Dong Y, Mo X, Hu Y. Epidemiological characteristics of 2143 pediatric patients with 2019 coronavirus disease in China. Pediatrics 2020;145:e20200702.

26 CDC COVID-19 Response Team, Chow N, Fleming-Dutra K. Preliminary Estimates of the Prevalence of Selected Underlying Health Conditions Among Patients with Coronavirus Disease 2019
- United States, February 12-March 28, 2020. MMWR Morb Mortal Wkly Rep 2020;69:382-6.

27 Shapiro SS, Wilk MB. An analysis of variance test for normality (complete samples). Biometrika 1965;52:591-611.

28 Conover WJ, Iman RL. On multiple-comparisons procedures, 1979.

29 Pohlert T. The pairwise multiple comparison of mean ranks package extended (PMCMRplus. R package, 2020.

30 Brown LD, Cai TT, DasGupta A. Interval estimation for a binomial proportion. Statistical science 2001:101-17.

31 Dorai-Raj S. binom: binomial confidence intervals for several parameterizations. 1.1-1. R package, 2014.

32 R Core Team. R: a language and environment for statistical computing. Vienna, Austria: R Foundation for Statistical Computing, 2020.

33 Nyabadza F, Chirove F, Chukwu CW, et al. Modelling the potential impact of social distancing on the COVID-19 epidemic in South Africa. Comput Math Methods Med 2020;2020:5379278.

34 Siraj A, Worku A, Berhane K, et al. Early estimates of COVID-19 infections in small, medium and large population clusters. BMJ Glob Health 2020;5.

35 Dahab M, Van Zandvoort K, Flasche S. COVID-19 control in lowincome settings and displaced populations: what can realistically be done? Confl Health 2020;14:1-6.

36 Widders A, Broom A, Broom J. SARS-CoV-2: the viral shedding vs infectivity dilemma. Infect Dis Health 2020;25:210-5.

37 Casey M, Griffin J, McAloon CG. Estimating pre-symptomatic transmission of COVID-19: a secondary analysis using published data. MedRxiv 2020

38 Bullock J, Cuesta-Lazaro C, Quera-Bofarull A. Operational response simulation tool for epidemics within refugee and IDP settlements. medRxiv 2021.

39 HERNANDEZ-SUAREZ CM, Verme P, Radyakin S, et al. COVID-19 outbreaks in refugee camps. A simulation study. medRxiv 2020

40 Gilman RT, Mahroof-Shaffi S, Harkensee C, et al. Modelling interventions to control COVID-19 outbreaks in a refugee cAMP. BMJ Glob Health 2020;5.

41 Pascual-García A, Klein J, Villers J, et al. Empowering the crowd: feasible strategies to minimize the spread of COVID-19 in highdensity informal settlements. medRxiv 2020.

42 Arenas A, Cota W, Gómez-Gardenes J. A mathematical model for the spatiotemporal epidemic spreading of COVID19. MedRxiv 2020.

43 Diop BZ, Ngom M, Pougué Biyong C, et al. The relatively young and rural population may limit the spread and severity of COVID-19 in Africa: a modelling study. BMJ Glob Health 2020;5.

44 Mukumbang FC. Are asylum seekers. refugees and foreign migrants considered in the COVID-19 vaccine discourse? BMJ Glob Health 2020;5.

45 Li Q, Guan X, Wu P, et al. Early transmission dynamics in Wuhan, China, of novel coronavirus-infected pneumonia. N Engl J Med. 2020;382:1199-207. 03.

46 Ashcroft P, Huisman JS, Lehtinen S, et al. COVID-19 infectivity profile correction. Swiss Med Wkly 2020;150:w20336.

47 Wölfel R, Corman VM, Guggemos W, et al. Virological assessment of hospitalized patients with COVID-2019. Nature 2020;581:465-9.

48 Wang D, Hu B, Hu C, et al. Clinical characteristics of 138 hospitalized patients with 2019 novel coronavirus-infected pneumonia in Wuhan, China. JAMA 2020;323:1061-9.

49 Byambasuren O, Cardona M, Bell K, et al. Estimating the extent of asymptomatic COVID-19 and its potential for community transmission: systematic review and meta-analysis. Official Journal of the Association of Medical Microbiology and Infectious Disease Canada 2020;5:223-34.

50 Calvot T, Merat C. Hidden victims of the Syrian crisis: disabled, injured and older refugees. London: HelpAge International and Handicap International, 2014. 